\title{
The Cytoarchitecture of the Inferior Colliculus of Two Species of Bats: Noctilio leporinus (Fish Eating) and Phyllostomus Hastatus (Carnivorous/ Omnivorous)
}

\author{
Isanna Gibbons ${ }^{1}$, Venkatesan Sundaram ${ }^{* 2}$, Andrew Adogwa ${ }^{3}$, Abayomi Odekunle ${ }^{4}$ \\ ${ }^{1,2,3}$ Department of Basic Veterinary Sciences, School of Veterinary Medicine, Faculty of Medical Sciences, The University of \\ the West Indies, Trinidad, Trinidad and Tobago \\ ${ }^{4}$ Department of Preclinical Sciences, School of Medicine, Faculty of Medical Sciences, The University of the West Indies, \\ Trinidad,Trinidad and Tobago \\ 'trinimaican2501@yahoo.com; ${ }^{* 2}$ drvenkat1971@gmail.com; ${ }^{3}$ Adogwa01@yahoo.com; ${ }^{4}$ abayomi.odekunle@ sta.uwi.edu
}

\begin{abstract}
The study was done to compare the cytoarchitecture of two species of bats to ascertain whether echolocation has a bearing on the development of the inferior colliculus. Six bats each of Noctilio leporinus and Phyllostomus hastatus were used for the study. The brains of these bats were processed by double embedding, serially sectioned at $10 \mu \mathrm{m}$ and stained with cresyl fast violet. The inferior colliculus measured $1200 \pm 90 \mu \mathrm{m}$ in length in $N$. leporinus bat and $1120 \pm 63 \mu \mathrm{m}$ in $P$. hastatus bat. The inferior colliculus of the bats is subdivided into three parts: dorsomedial, ventromedial and the peripheral. Two types of cells are most common in the inferior colliculus of the bats: multipolar and oval. The inferior colliculus is very large in the two species of bats compared to other animals which do not echolocate and which may not have as good a sense of hearing as the bat. It is larger in the $N$. leporinus than in the $P$. hastatus bat suggesting that $N$. leporinus depends more on echolocation than $P$. hastatus. The large inferior colliculus in these bats may be related to an acute sense of hearing in these animals.
\end{abstract}

Keywords- Inferior Colliculus; Cytoarchitecture; Bats

\section{INTRODUCTION}

Bats need to hear in order to orient themselves during flight. Therefore, bats produce sounds whose frequency is beyond the range of human hearing [1]. These sounds known as echolocation are used by bats not only for orientation in flight but also for obstacle avoidance as well as for foraging [2,3]. Studies have linked the foraging behaviours of bats to different types of echolocation signals [4]. The auditory pathway includes the inferior colliculus. Both monaural and binaural pathways end in the inferior colliculus. The inferior colliculus, thus, plays a very crucial role in audition because it is the main relay centre for both the ascending fibres from the lateral lemniscus as well as the descending fibres from the auditory cortex [5]. It also receives inputs via bilateralization between both inferior colliculi [6]. The inferior colliculus projects to the ipsilateral medial geniculate body which then projects to the auditory cortex.

Literature on cytoarchitectural studies in the two species of bats is not available. This study is intended to compare the cytoarchitecture of the two species of bats to ascertain whether echolocation has a bearing on the development of the inferior colliculus.

\section{MATERIALS AND METHODS}

Six bats of each species (Noctilio leporinus and Phyllostomus hastatus) were collected. Each bat was anaesthetized using 0.2 mlsof $1: 1$ solution of $2 \%$ xylazine and $10 \%$ ketamine intraperitoneally. The brains were removed carefully and stored in $10 \%$ formalin.

The brains were obtained from bats being used for other studies. The research protocol was approved by the ethics committee of the Faculty of Medical Sciences. After fixation, the brains were processed manually and double embedded according to the method previously described [7] as follows:

$\begin{array}{ll}80 \% \text { alcohol } & \text { 4days } \\ 95 \% \text { alcohol I } & 1 \text { day } \\ 95 \% \text { alcohol II } & 1 \text { day } \\ 95 \% \text { alcohol III } & 1 \text { day } \\ \text { Absolute alcohol/ether I } & 9 \text { hours }\end{array}$




$\begin{array}{ll}\text { Absolute alcohol/ether II } & 9 \text { hours } \\ \begin{array}{l}1 \% \text { Celloidin } \\ \text { Chloroform I } \quad \text { I days } \\ \text { Chloroform II }\end{array} & 8 \text { hours } \\ \text { Paraffin }\left(56-58^{\circ} \mathrm{C}\right) \text { I } & 18 \text { hours } \\ \text { Paraffin }\left(56-58^{\circ} \mathrm{C}\right) \text { II } & 12 \text { hours } \\ \end{array}$

The tissues were then left at room temperature overnight. They were then melted out of paraffin and placed in fresh paraffin for 2 hours in a vacuum under pressure of 20 inches of mercury. The tissues were blocked and sectioned transversely at a thickness of $10 \mu \mathrm{m}$ using the rotary microtome. The slides were stained using cresyl fast violet. Digital images of the inferior colliculus, including the size and shapes of the cells were captured with the Olympus BX51 system microscope equipped with the Olympus DP71 camera.

\section{RESULTS}

\section{A. Inferior Colliculus of NoctilioLeporinus Bat}

The most caudal end of the inferior colliculus of the $N$. leporinus bat is in the medulla oblongata at the level of the motor nucleus of the trigeminal nerve (Fig. 1A). The caudal third of the inferior colliculus is subdivided into dorsal and ventral parts. The dorsal part comprises mainly medium-sized, light staining round cells measuring $7.5 \mu \mathrm{m}-12 \mu \mathrm{m}$ in diameter (Fig. $1 \mathrm{~B}$ ). The ventral part comprises large, light staining multipolar cells measuring $15 \mu \mathrm{m}$ and $25 \mu \mathrm{m}$ (Fig. 1C). Small, dark staining, round cells (measuring between $2.5 \mu \mathrm{m}$ and $5.0 \mu \mathrm{m}$ in diameter) are abundant dispersed throughout the caudal third of the nucleus (Fig. 1D).
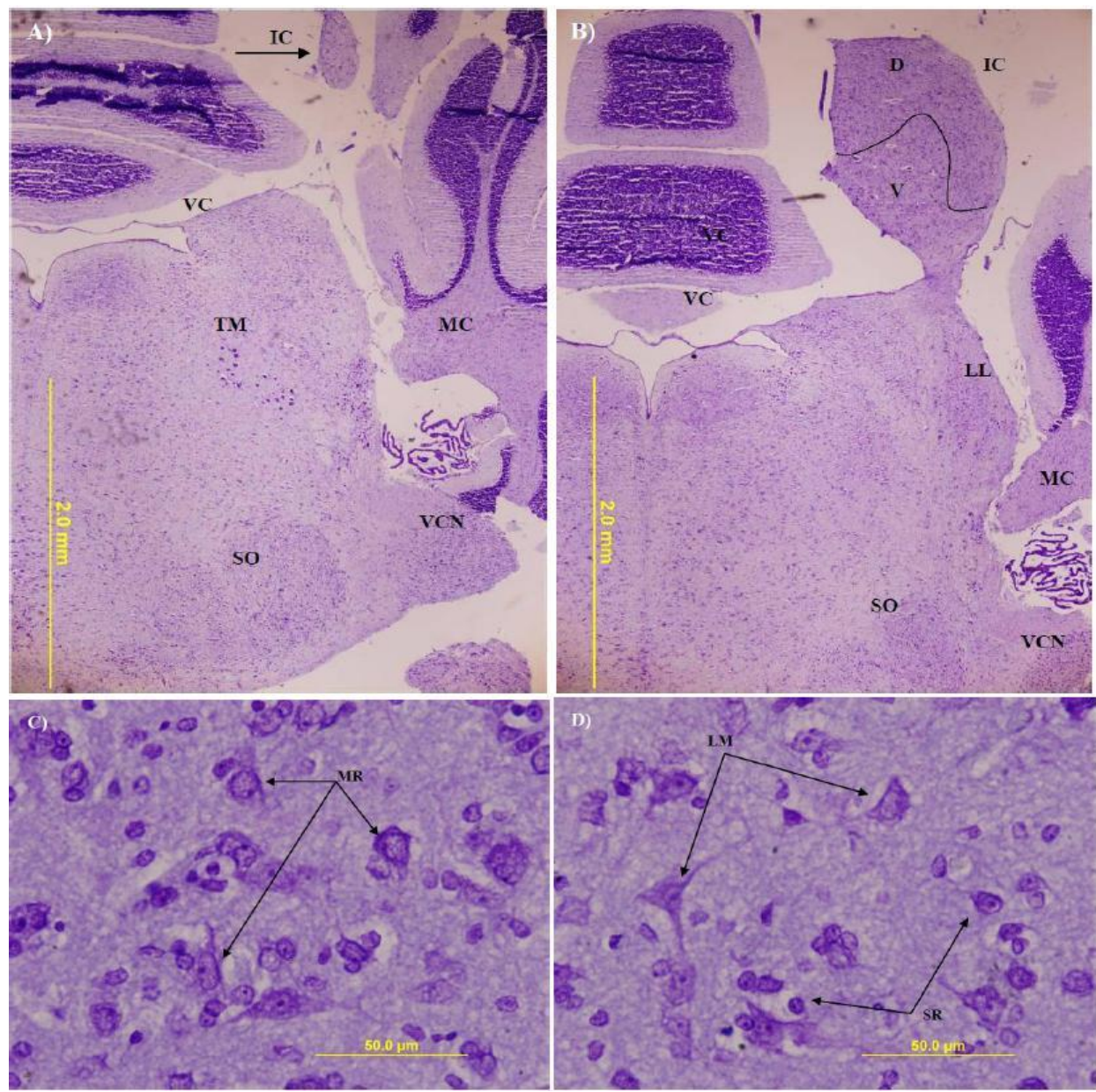

Fig. 1 Transverse section of the brainstem of the Noctilio leporinus bat. A). Most caudal end of the inferior colliculus at the level of motor nucleus of trigeminal nerve. B). Caudal third of the inferior colliculus at the level of trapezoid body. C). Medium sized, light-staining round cells (MR) measuring between $7.5 \mu \mathrm{m}$ and $12.5 \mu \mathrm{m}$ in diameter in the dorsal division. D). Large sized, light-staining multipolar cells (LM) measuring between $15.0 \mu \mathrm{m}$ and $25.0 \mu \mathrm{m}$ in diameter and Small sized dark-staining, round cells (SR) measuring between $2.5 \mu \mathrm{m}$ and $5.0 \mu \mathrm{m}$ in diameter in the ventral division of the caudal third of the inferior colliculus. TM - Motor nucleus of the trigeminal nerve, MC - Middle cerebellar peduncle, SO - Superior olivary complex, VC - Vermis of the cerebellum, IC - Inferior colliculus, VCN -Ventral cochlear nucleus, LL-Lateral lemniscus, D-Dorsal part of Inferior colliculus, V-Ventral part of the inferior colliculus. Scale bar A \& B $=2 \mathrm{~mm}$ and C \& D =50mm. 
The middle third of the inferior colliculus is at the level of the nucleus of the trapezoid body. The lateral lemniscus is seen at this level, as a very prominent protrusion on the lateral aspect of the brainstem, just dorsal to the middle cerebellar peduncle. In this region the inferior colliculus is subdivided into dorsolateral and ventromedial parts; the dorsolateral part is further subdivided into superficial and deep layers (Fig. 2A).Mainly the round, medium, light-staining cells are found in this part (Fig. 2C). The main cells of the ventral part are the round light-staining cells measuring between $7.5 \mu \mathrm{m}$ and $12.5 \mu \mathrm{m}$ in diameter, and the small dark-staining cells of about $5 \mu \mathrm{m}$ in diameter (Fig. 2D).
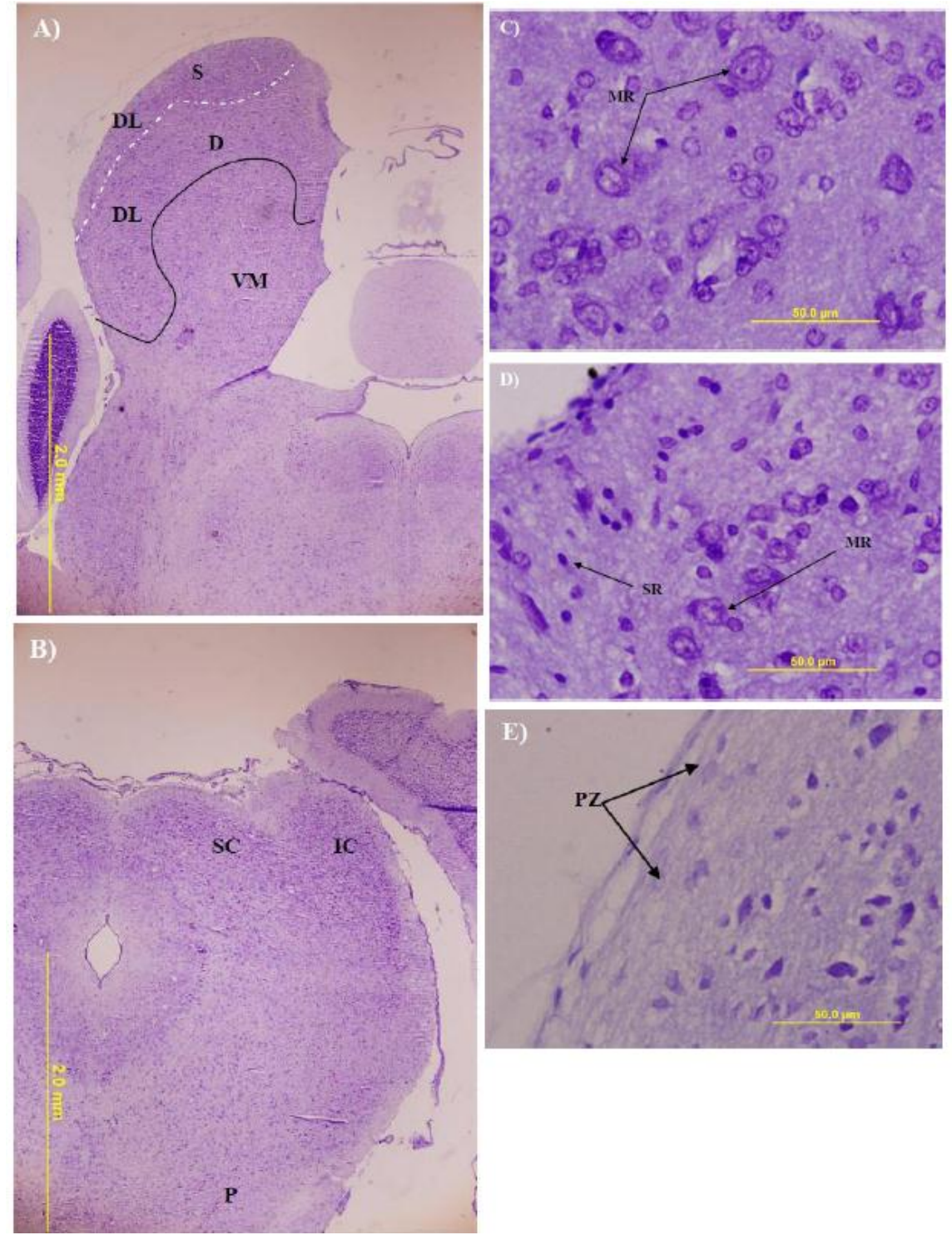

Fig. 2 Transverse section of brainstem of the Noctilio leporinus bat. A). Middle third of the inferior colliculus at the level of the nucleus of the trapezoid body showing the dorsolateral (DL) and the ventromedial (VM) parts. B). Most caudal part of the rostral colliculus at the level of pons C). Medium sized,

light-staining round cells (MR) measuring between $7.5 \mu \mathrm{m}$ and $12.5 \mu \mathrm{m}$ in the dorsolateral part. D). Medium, light-staining, round cells (MR) measuring between $7.5 \mu \mathrm{m}$ and $12.5 \mu \mathrm{m}$ and small, dark-staining round cells (SR) measuring between $2.5 \mu \mathrm{m}$ and $5.0 \mu \mathrm{m}$ in diameter in the ventrolateral part. E). Small oval light-staining cells in the cell-sparse peripheral zone (PZ) of the rostral third of the inferior colliculus measuring $7.5 \mu \mathrm{m}$.S-Superficial layer of dorsolateral part of inferior colliculus, D-Deep layer of dorsolateral part of the inferior colliculus, P-Pons, SC-Superior colliculus, IC-Inferior colliculus. Scale bar A\&B= $2 \mathrm{~mm}$ and $\mathrm{C}, \mathrm{D} \& \mathrm{E}=50 \mathrm{~mm}$

The rostral one-third of the inferior colliculus, at the level of the commissure of the inferior colliculus is subdivided into dorsolateral, ventromedial and a peripheral zones. The peripheral zone is the least cellular and comprise mainly of cells that are approximately $7.5 \mu \mathrm{m}$ in diameter (Fig. 2E).The dorsolateral part is densely populated with dark-staining multipolar cells measuring between $9 \mu \mathrm{m}$ and $18 \mu \mathrm{m}$ in diameter. The ventromedial division is made up of medium and large light-staining cells measuring between $15 \mu \mathrm{m}$ and $25 \mu \mathrm{m}$ in diameter. This part appears less dense than the dorsolateral part. At the level of the pons, where the superior colliculus appears, the inferior colliculus is significantly reduced in size (Fig. 2B).

The inferior colliculus is $1200 \pm 96 \mu \mathrm{m}$ in length extending from the medulla oblongata to the superior colliculus in the pontine region. 


\section{B. Inferior Colliculus of the PhyllostomusHastatus Bat}

The caudal one-third of the inferior colliculus is located in the region of the middle cerebellar peduncle. The caudal one-third of the inferior colliculus is subdivided into three parts: dorsal, ventral and peripheral (Fig. 3A). The dorsal part is densely populated with dark-staining, multipolar cells measuring approximately $20 \mu \mathrm{m}$ in diameter. The ventral part comprises similar cells but is less dense. The peripheral part is a cell-sparse area containing few small, round light-staining cells of approximately $5 \mu \mathrm{m}$ in diameter (Fig. 3B).

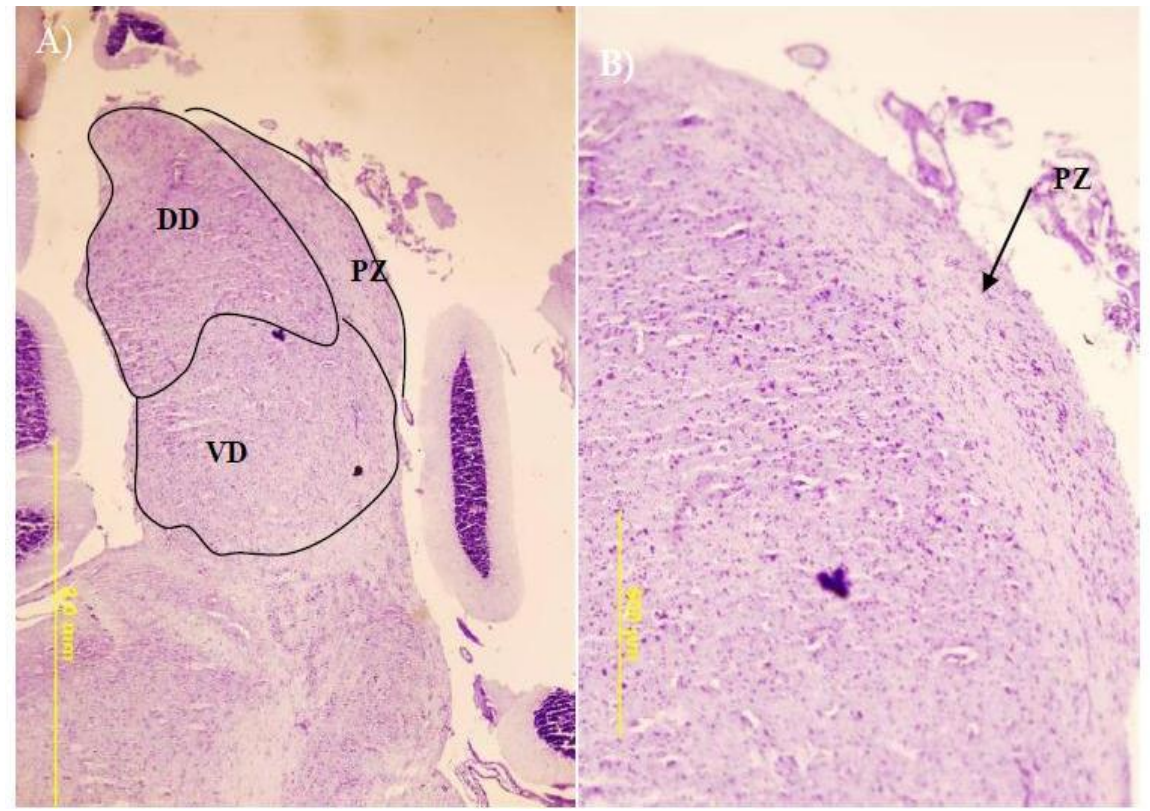

Fig. 3 Transverse section of brain stem of the Phyllostomus hastatus bat. A). Caudal third of the inferior colliculus at the level of the middle cerebellar peduncle showing dorsal (DD), ventral (VD) and peripheral (PZ) parts. B). Showing the cell-sparse nature of peripheral zone. Scale bar A\&B=2mm.

The middle third of the inferior colliculus is at the level of the nucleus of the trapezoid body and continues to be subdivided into three parts viz., dorsolateral, ventromedial and peripheral (Fig.4 A\&B). The dorsolateral part is more densely populated than the ventromedial part. Light-staining round cells measuring approximately $12.5 \mu \mathrm{m}$ in diameter are found in this region while the ventromedial region comprises large, dark-staining multipolar cells measuring between $17.5 \mu \mathrm{m}$ and $25 \mu \mathrm{m}$ in diameter (Fig. 4C\&D).
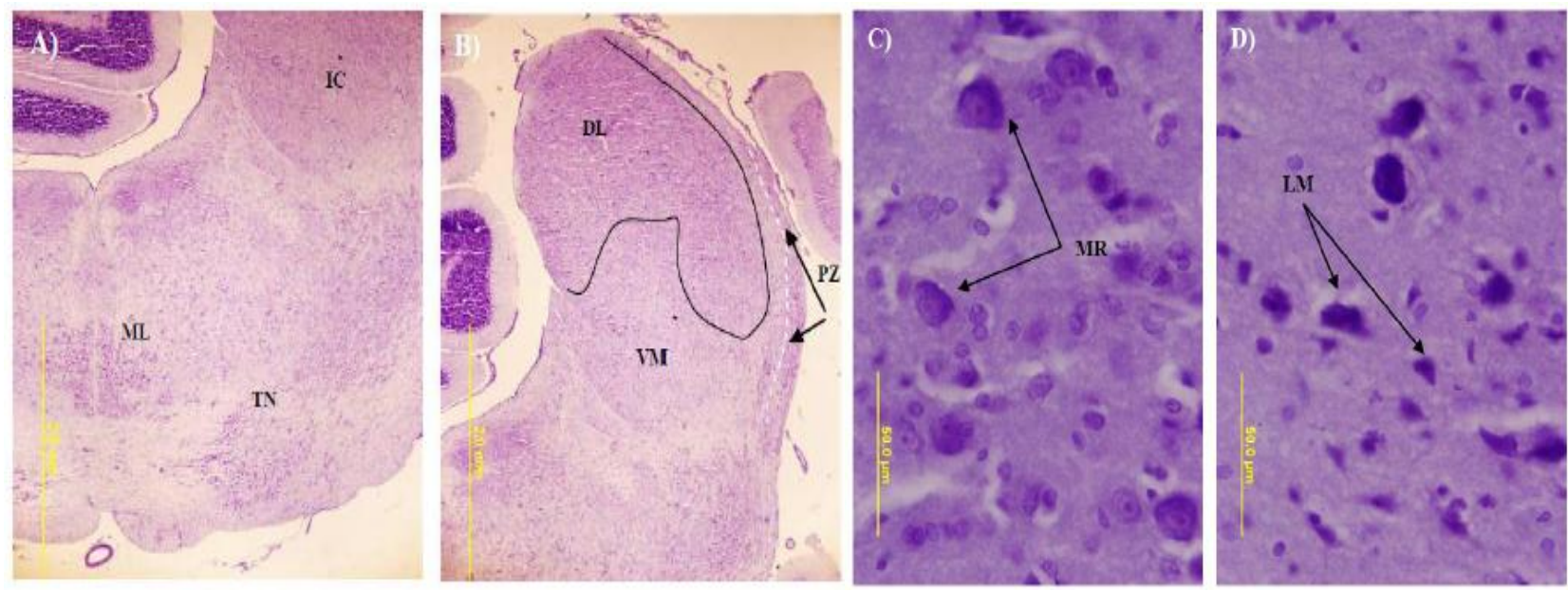

Fig. 4 Transverse section of brain stem of the Phyllostomushastatus bat.A) and B).Showing the middle third of the inferior colliculus at the level of the nucleus of the trapezoid body. The inferior colliculus is divided into dorsolateral (DL), ventromedial (VM) and periphery (PZ) parts. C). Light-staining, round cells

$(12.5 \mu \mathrm{m}$ in diameter) in the dorsolateral division and D). Large, dark-staining, multipolar cells (17.5 $\mu \mathrm{m}, 25.0 \mu \mathrm{m}$ in diameter) in the ventromedial division of the middle third of the inferior colliculus. IC - Inferior colliculus, $\mathrm{TN}$ - Nucleus of the trapezoid body, Scale bar A \& $\mathrm{B}=2 \mathrm{~mm}$ and $\mathrm{C} \& \mathrm{D}=50 \mathrm{~mm}$.

The rostral one-third of the inferior colliculus contains mainly large, multipolar, dark-staining cells and is not subdivided into three parts as in the caudal one-third and middle-third. The periphery is still cell-sparse and contains large, round, light-staining cells (Fig. 5C). The inferior colliculus is greatly diminished in size at the point where the superior colliculus becomes visible (Fig. 5 A\&B). 

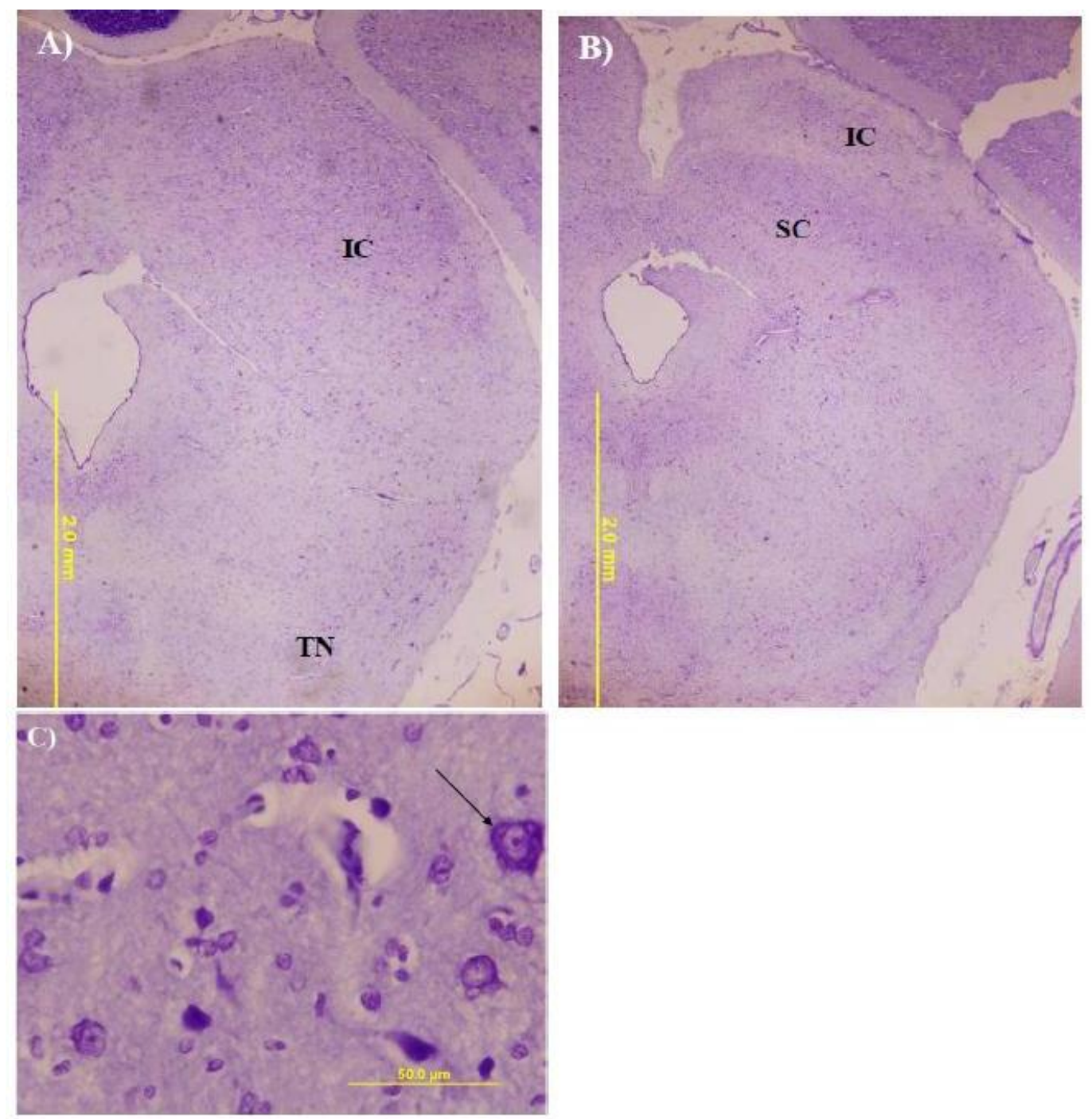

Fig. 5 Transverse section of brain stem of the Phyllostomushastatus bat. A \& B showing the diminishing inferior colliculus (IC) (from A to B, heading rostrally from the level of nucleus of trapezoidal body to the superior colliculus) as the superior colliculus (SC) becomes visible. B.Showing the large, round, light-staining cells (arrow) found in the periphery of the rostral third of the inferior colliculus. Scale bar $A \& B=2 \mathrm{~mm}$ and $\mathrm{C}=50 \mathrm{~mm}$.

The inferior colliculus of the $P$. hastatus bat is $1120 \pm 63 \mu \mathrm{m}$ in diameter from the caudal end at the level of the middle cerebellar peduncle to the rostral end of the superior colliculus.

\section{IV.DISCUSSION}

The inferior colliculus is the principal midbrain nucleus of the auditory pathway. The nucleus is one of the most metabolically active nuclei in the brain [8]. Generally the auditory nuclei of echolocating animals as well as animals with an excellent sense of hearing are found to be significantly enlarged [9]. The medial geniculate body, the inferior colliculus, the superior olivary complex, the nucleus of the trapezoid body and the lateral lemniscus are all very prominent in the marmoset compared to those nuclei found in man and non-human primates [10]. In the echolocating birds, the nucleus mesencephalicus lateralis pars dorsalis, which is homologous to the inferior colliculus, is also reported to be very large [5]. Many studies have been done on whales, dolphins and some cetaceans that echolocate, and the tecta of these animals are generally well developed and, more specifically, the inferior colliculi in these animals are very large [11]. The inferior colliculus of dolphins is about twelve times larger than that of humans. The inferior colliculus of the two bats in this study, as in other animals that echolocate, are very large. The inferior colliculus of the $N$. leporinus bat is larger than that of $P$. hastatus. It is suggested, here, that this is because the $N$. leporinus bat, whichis carnivorous and feeds on fishes, depends on echolocation more than the P. hastatus bat which is carnivorous/ omnivorous.

The inferior colliculus in the mouse comprises mainly of three subdivisions: central nucleus, dorsal cortex and lateral cortex [13]. Similar subdivisions have been seen in the present study (as ventral nucleus, dorsolateral part the peripheral part). Projections from the ventral cochlear and the contralateral superior olivary complex terminate on the central nucleus, and projections from the auditory cortex terminate on the dorsal cortex and superficial layer of the external cortex [13, 14]. The ventrolateral and dosolateral nuclei are very large in the two bats of this study. The parts also have high numbers of both oval 
and multipolar cells, suggesting that which are responsible for projections to higher centres. The lateral cortex (peripheral part of this study) receives inputs from and sends projections to the superior colliculus $[15,16,17]$ and, may play a major role in multisensory integration [18].

\section{CONCLUSIONS}

The inferior colliculus measured $1200 \pm 90 \mu \mathrm{m}$ in length in $N$. Leporinus bat and $1120 \pm 63 \mu \mathrm{m}$ in P. hastatus bat. The inferior colliculus of the bats is subdivided into three parts: dorsomedial, ventromedial and the periphery. Two types of cells are most common in the inferior colliculus of the bats: multipolar and oval. The inferior colliculus is very large in the two species of bats compared to other animals which do not echolocate and which may not have as good a sense of hearing as in the bat. It is larger in the $N$. leporinus bat than in the P. hastatus bat may be because $N$. leporinus depends more on echolocation than $P$. hastatus. The large inferior colliculus in these bats may be related to an acute sense of hearing in these animals.

\section{REFERENCES}

[1] G. Neuweiler and E. Covey, The Biology of Bats. Oxford University Press, USA, 2000.

[2] M.B. Fenton and J.H. Fullard, "The influence of moth hearing on bat echolocation strategies", J. Comp. Physiol., vol. 132, pp.77-86, 1979.

[3] E.K.V. Kalko and H.U. Schnitzer, "Plasticity in echololocating signals of European pipistrelle bats in search flight: implications for habitat use and prey detection", Behav. Ecol. Sociobiol., vol 33, pp. 415-428, 1999.

[4] G.Neuweiler, "Foraging ecology and audition in echolocating bats", Trends EcolEvol., vol.4 (6), pp.60-66, 1989.

[5] A.N. Iwaniuk, D.H. Clayton, and D.R.W. Wylie, "Echolocation, vocal learning, auditory localization and the relative size of the avian auditory midbrain nucleus (MLD)", Behavioural Brain Res.,vol.167,pp.305-317, 2006.

[6] M.S. Malmierca, M.A. Merchan, C.K. Henkel and D.L. Oliver, "Direct projections from cochlear nuclear complex to auditory thalamus in the rat", J. Neurosci., vol 22(24), pp.10891-10897, 2002.

[7] A. Adogwa, and A. Lakshminarasimhan, "The morphology and cytoarchitecture of the red nucleus of the one-humped camel (Camelus dromedaries)", J. fur Hirnforrschung, vol. 23, pp. 627 -633, 1982.

[8] W.M. Landau, J.R.W.H. Freygang, L.P. Roland, L.Sokoloff, and S.S. Ketty, "The local circulation of the living brain; values in the unanaesthetized and anasthetized cat", Transactions of the American Neurol. Asso., vol. 80, pp.125-129, 1955.

[9] J.M. Zook, and J.H. Casseday, "Cytoarchitecture of auditory system in lower brainstem of the moustache bat, Pteronotusparnellii", J. Comp. Neurol., vol. 207(1), pp. 1-13, 1982.

[10] F.P. Reis, and E.A. Erhart, "The brain of the marmoset (Callithrix jacchus)”, Acta Anat., vol. 103, pp.350-357, 1979.

[11] L. Marino, C.C. Sherwood, B.N. Delman, C.Y. Tang, T.P. Naidich, and P.R. Hof, "Neuroanatomy of the killer whale (Orcinus orca) from magnetic resonance images", Anat. Rec., vol. 281(2),pp.1256-1263, 2004.

[12] T. H. Bullock and V.S. Gurevich, "Soviet literature on the nervous system and psychobiology of cetacean”, Intl. Rev. Neurobiol., vol. 21, pp. 47-127, 1979.

[13] F.H. Willard and D.K. Ryugo, The Auditory Psychobiology of the Mouse. J.F. Williot. Ed. Charles C Thomas Publisher, Springfield, Illinois, 1983.

[14] F.H. Willard and G.F. Martin, "The auditory brainstem nuclei and some of their projections to the inferior colliculus in the North American opossum", Neurosci., vol. 10(4),pp.1203. 1983.

[15] A.J. King, J.W.H. Schnupp and I.D. Thompson, "Signals from the superficial layers of the superior colliculus enable the development of the auditory space map in the deeper layers", J. Neurosci., vol. 18, pp. 9394-9408, 1998.

[16] M.S. Malmierca, "The Inferior Colliculus: A Center for Convergence of Ascending and Descending Auditory Information", Neuroembryol. Ageing, vol. 3, pp. 215-229, 2004.

[17] J.W.H. Schnupp, and A.J. King, "Coding for auditory space in the nucleus of the brachium of the inferior colliculus in the ferret", J. Neurophysiol., vol. 78(5), pp. 2717-2731, 1997.

[18] W.C. Loftus, M.S. Malmierca, D.C. Bishop, and D.L. Oliver, "The cytoarchitecture of the inferior colliculus revisited: a common organization of the lateral cortex in rat and cat", Neurosci. vol.154, pp.196-205, 2008. 